\title{
Prevention of oxidative damage in the rat jejunal mucosa by pectin
}

\author{
BY RON KOHEN*, VERED SHADMI, ANGEL KAKUNDA \\ AND ABRAHAM RUBINSTEIN \\ The Hebrew University of Jerusalem, School of Pharmacy, PO Box 12065, Jerusalem 91120, Israel
}

(Received 11 September 1991 - Accepted 4 June 1992)

\begin{abstract}
The role of the soluble non-starch polysaccharide pectin in the prevention of oxidative damage induced by peroxy, superoxide and hydroxyl radicals to the rat jejunal mucosa was studied. The oxidative stress was introduced to the rat jejunal mucosa by means of a closed-loop perfusion system and was characterized biochemically by monitoring the enterocyte activity of the enzyme lactate dehydrogenase (EC 1.1.1.27) and the $\mathrm{K}^{+}$level. Aqueous solutions of pectin were perfused into the rat jejunum before the oxidative stress inducers. The possible protection effect was evaluated by comparing the mucosal integrity (as measured by biochemical variables) to the values obtained after perfusion with the oxidative stress inducers only. We found that: $(a)$ mucosal damage was detected following the perfusion of peroxy and hydroxyl radicals in the rat jejunum, but not following perfusion of the superoxide radical; $(b)$ a significant reduction in the mucosal damage was noted when pectin was perfused before the perfusion with the peroxy radical induction; $(c)$ full protection against the mucosal damage induced by hydroxyl radicals was achieved when pectin was perfused before the damage induction.
\end{abstract}

Oxidative stress: Mucosal damage: Free radicals: Pectin: Antioxidants

Oxygen free radicals and other $O$ species have been claimed to be involved in many biologically deleterious processes such as ageing and inflammation, and in diseases such as cancer (Ames et al. 1981; Ames, 1983; Halliwell \& Gutteridge, 1985). Reactive O species can cause direct and indirect damage to essential macromolecules, e.g. membrane disruption (Korbashi et al. 1986), enzyme inactivation (Oliver et al. 1987) and DNA damage (Pryor, 1976). There is a growing body of experimental information that suggests that these reactive species mediate some of the cellular injury associated with radiation enteritis, ischaemic bowel diseases, gastric ulceration and inflammatory bowel diseases (Granger et al. 1986; Grisham et al. 1987). The gastrointestinal mucosa is exposed to oxidants produced within the lumen and in the epithelium cells. Potential source of luminal oxidants include ingested food, catalase ( $E C$ 1.11.1.6)-negative bacteria, oxidases and substrates from desquamated cells, saliva and cigarette smoke and tar (Cross et al. 1984; Grisham et al. 1987).

Peroxy radical (ROO*), lipid hydroperoxide $(\mathrm{ROOH})$ and other reactive metabolites are produced by lipid peroxidation. The lipid hydroperoxide is unstable and easily decomposed into products such as aldehydes, enals, alkoxy radicals, endoperoxide and other toxic metabolites (Chance et al. 1979; Halliwell \& Gutteridge, 1985). During the oxidation of dietary fatty acids in the peroxisomes $\mathrm{H}_{2} \mathrm{O}_{2}$ is formed (Chance et al. 1979; Ames, 1983; Halliwell \& Gutteridge, 1985). The $\mathrm{H}_{2} \mathrm{O}_{2}$ can either cause damage by itself, or can serve as a source for other reactive metabolites, such as the hydroxyl radical $\left(\mathrm{OH}^{*}\right)$, via the metalmediated Haber-Weiss reaction (Navok \& Chevion, 1984). Another source for the 
production of $\mathrm{H}_{2} \mathrm{O}_{2}$ is the spontaneous and catalytic dismutation of superoxide radicals. These radicals can be generated as a consequence of the metabolism (reduction of $\mathrm{O}_{2}$ in stages in the mitochondria) or as a result of enzyme activity, e.g. xanthine oxidase (EC 1.1.3.22).

The production of reactive $O$ species during the metabolism of dietary fat can explain some biological damage such as loss of cell membrane function, inactivation of membranebound enzymes and inactivation of essential molecules located inside the cell. This supports the assessment that high fat consumption is associated with high incidence of colon cancer (Kinlen, 1983). Indeed, recent mutagenic tests have shown that a large amount of fat in the diet is a promoter and a presumptive carcinogen (Kinlen, 1983; Ames \& Saul, 1985). Apart from colon cancer, other injuries associated with the O-reactive metabolites, such as ulcer diseases, inflammation and ischaemic bowel diseases, may occur throughout the entire gastrointestinal tract (Szabo \& Pfiffer, 1989).

Characterization of oxidative damage in biological samples may be carried out in various ways: they include histological and biochemical methods. In the present study we chose to follow two biochemical variables which may indicate membrane status and function. These variables are the cellular $\mathrm{K}^{+}$level and the activity of a cellular enzyme lactate dehydrogenase $(E C 1.1 .1 .27 ; \mathrm{LDH})$. It has been shown before that these biochemical markers are suitable for evaluation of oxidative damage in biological samples (Samuni et al. 1991; Wolfgang et al. 1991). Oxidative damage to cell membrane will result in loss of several membrane functions. As a result, leakage of cellular components such as $\mathrm{K}^{+}$ions and $\mathrm{LDH}$ occurs.

Nutritional and epidemiological studies have indicated that proper dietary practices may play an important role in cancer prevention, and that a general increase in consumption of fibre-rich cereals, vegetables and fruit would be prudent (Bijlani, 1985). The exact role of dietary fibres (preferably known as non-starch polysaccharides (NSP)) in the prevention of intestinal diseases and colon cancer has not been totally clarified. Several suggestions have been made, but none can satisfactorily explain the mechanism of their action. Excluding their influence on large bowel motility, faecal weight and faecal composition (Burkitt, 1971; Anderson, 1985), various other physiological effects are associated with NSP consumption. Worth noting are the reduction in blood cholesterol levels, the alteration in glucose absorption, and impairment of mineral $(\mathrm{Ca}, \mathrm{Zn}$ and $\mathrm{Fe}$ ) absorption, which are related to the gel-forming soluble NSP such as pectin and guar gum (Burkitt, 1971; Cummings et al. 1979; Anderson, 1985; Bijlani, 1985; Trowell \& Burkitt, 1985).

Pectins are predominantly linear polymers of mainly $\alpha$-(1-4)-linked D-galacturonic acid residues interrupted by 1,2-linked L-rhamnose residues. They are extracted from plant primary cell walls and are used as gelling and thickening agents in food technology (Towle \& Christensen, 1973). It is generally accepted that pectin may lower blood glucose levels and serum cholesterol values in humans (Flourie et al. 1984; Anderson, 1985; Bijlani, 1985). These physiological effects are related in part to delay in gastric emptying, and increase in the intraluminal unstirred-layer viscosity and thickness. A related study (Blackburn \& Johnson, 1983) describes how another soluble NSP, guar gum, reduced the absorption of low concentrations of glucose and inhibited fluid absorption in the perfused rat intestine. It was suggested that the guar gum formed a viscous layer close to the intestinal mucosa which slowed down the solutes' diffusion from the lumen.

The purposes of the present study were: $(a)$ to evaluate and quantify the induced oxidative damage to the rat jejunal mucosa by perfusion of peroxy, superoxide and hydroxyl radical inducers, and $(b)$ to elucidate the potential role of pectin in prevention of the induced oxidative damage in the rat jejunal mucosa. 


\section{EXPERIMENTAL PROCEDURES}

All the materials were purchased from Sigma, unless otherwise mentioned in the text.

\section{Induction of oxidative stress}

The exposure of the rat jejunum epithelial tissue to oxidative stress was achieved by perfusing aqueous solutions of the active $O$ species generators in a closed intestinal loop of anaesthetized rat as described below. This method was chosen because: $(a)$ it allows the induction of the mucosal oxidative stress in the luminal compartment of the intestine, and (b) the damage is induced to a tissue which continues to function close to the normal physiological conditions (primarily because the blood flow is not disrupted).

$R O O^{\circ}$. These were induced by perfusing aqueous solutions of $2,2^{\prime}$-azobis (2-amidinopropane dihydrochloride) (AAPH; Polysciences, Warington, PA, USA). This substance is a generator of a continuous efflux of ROO' (Yamamoto et al. 1985). The rate of ROO' formation from this initiator remains constant at a given temperature. Once formed, it can initiate free-radical chain oxidation of lipids which will result in the production of lipid ROOH. Three different concentrations were used in separate studies: 25,50 and $100 \mathrm{mM}$. Since the radical formation flux is temperature dependent, the temperature of the perfusate was kept constant at $37^{\circ}$ using a temperature-controlled water-bath in which the solution reservoir and the system tubing were constantly immersed.

Superoxide radicals. These were generated by xanthine and xanthine oxidase as described elsewhere (Halliwell, 1990). The production of superoxide radicals was ascertained by following the reduction of cytochrome $\mathrm{c}$. The kinetics of this reaction was followed spectrophotometrically at $550 \mathrm{~nm}$ (Uvikon 930; Kontron, Zurich, Switzerland). Xanthine $(6 \mathrm{~mm})$ and xanthine oxidase $(3 \mathrm{U})$ were perfused into the rat jejunum in $50 \mathrm{~mm}$-phosphate buffer, $\mathrm{pH} 7 \cdot 2$, for $30 \mathrm{~min}$.

$O H^{\circ}$. These were generated by adding $10 \mathrm{~mm}$-ferrous sulphate chelated with EDTA $(1 \mathrm{~mm})$ to the mixture of xanthine $(6 \mathrm{~mm})$-xanthine oxidase $(3 \mathrm{U})$, as described elsewhere (Halliwell, 1990). This mixture was perfused into the rat jejunum in $50 \mathrm{~mm}$-phosphate buffer $\mathrm{pH} 7 \cdot 2$, for $30 \mathrm{~min}$.

\section{The perfusion system}

After an overnight fast, male Sabra rats (Lutsky et al. 1984), 200-230 g each, were anaesthetized by intraperitoneal injection of Equitensine solution (equivalent to $60 \mathrm{mg}$ sodium pentobarbitone $/ \mathrm{kg}$ ). The duodenum was exposed through a midline incision. An Lshaped glass cannula was inserted and secured with a silk suture $20 \mathrm{~mm}$ distal to the ligament of Treitz. A second cannula was placed in the same manner $150 \mathrm{~mm}$ distal to the first cannula. A closed-circulation perfusion loop was achieved by connecting the glass cannulas with a $0.3 \mathrm{~mm}$ i.d. $/ 1.5 \mathrm{~mm}$ o.d. Teflon tube through a metering pump (FMI model; RHSY, Oyster Bay, NY, USA), which was operated at a rate of $2 \mathrm{ml} / \mathrm{min}$. The perfused intestinal segment was kept outside the rat body without disrupting blood flow. The temperature of the exposed tissue was kept at $37^{\circ}$ with a $60 \mathrm{~W}$ bulb, and a gauze sponge wetted with saline $(9 \mathrm{~g} \mathrm{NaCl} / 1)$ kept the tissue moist (Lewis \& Fordtran, 1975; A. Rubinstein, A. Kakunda and R. Kohen, unpublished results).

Anaesthetized rats were killed at the end of each experiment by an intravenous injection of saturated aqueous $\mathrm{KCl}$ solution.

\section{The protective effect of pectin}

In separate control studies performed at the same time, saline and apple pectin (250-grade, $60.8 \%$ degree of esterification; BDH, Poole, Dorset; $20 \mathrm{~g} / 1$ ) in saline were perfused in a 
similar manner into the rat jejunum. These studies were done in order to watch for possible damage that may have occurred as a result of the perfusion procedure. The last set of perfusion studies included three different experiments: ( $a$ ) perfusion of $20 \mathrm{~g}$ apple pectin/1 saline ( $15 \mathrm{~min})$, followed by aqueous solutions of AAPH $(60 \mathrm{~min})$ in the following concentrations: 25,50 and $100 \mathrm{~mm}-\mathrm{AAPH}$ each; $(b)$ perfusion of $20 \mathrm{~g}$ apple pectin/1 saline $(15 \mathrm{~min})$, followed by xanthine $(6 \mathrm{~mm})$ and xanthine oxidase $(3 \mathrm{U})$ in $50 \mathrm{~mm}$-phosphate buffer, $\mathrm{pH} 7 \cdot 2$ for $30 \mathrm{~min}$; (c) perfusion of $20 \mathrm{~g}$ apple pectin/ 1 saline $(15 \mathrm{~min})$, followed by xanthine $(6 \mathrm{~mm})$-xanthine oxidase $(3 \mathrm{U})$ with $10 \mathrm{~mm}$-EDTA-chelated ferrous sulphate in $50 \mathrm{~mm}$-phosphate buffer, $\mathrm{pH} 7 \cdot 2$, for $30 \mathrm{~min}$.

The ability of the pectin to scavenge superoxide radicals in vitro was measured as follows: to a mixture of xanthine $(1.2 \mathrm{~mm})$, xanthine oxidase $(0.01 \mathrm{U})$ and cytochrome $\mathrm{c}(0.05 \mathrm{mM})$ in $50 \mathrm{~mm}$-phosphate buffer, $\mathrm{pH} 7.2$ the following concentrations of pectin in saline were added : $0,1 \cdot 5,4 \cdot 0$ and $6.0 \mu \mathrm{M}$. Cytochrome c reduction was followed spectrophotometrically at $550 \mathrm{~nm}$ (Uvikon 930; Kontron, Zurich, Switzerland).

\section{Characterization of the induced mucosal damage}

The extent of the damage induced to the intestine epithelial mucosa was characterized by monitoring the activity of the tissue enzyme LDH and the $\mathrm{K}^{+}$content of the enterocytes. It was postulated that damage to the mucosa will result in a leak of intracellular contents such as $\mathrm{K}^{+}$and $\mathrm{LDH}$. This would lead to lower levels of $\mathrm{K}^{+}$and lesser activity of cellular LDH compared with non-treated animals (A. Rubinstein, A. Kakunda and R. Kohen, unpublished results).

At the end of the perfusion $(60 \mathrm{~min}$ for $\mathrm{ROO}$, and $30 \mathrm{~min}$ for superoxide radicals and $\left.\mathrm{OH}^{*}\right)$ the perfused jejunal segment was separated from the anaesthetized animal and cut open. The epithelium mucosal layer was delicately scraped with the aid of a microscope slide, weighed, and rapidly transferred into a tissue-homogenization test-tube containing $2 \mathrm{ml}$ saline, kept in an ice bath. The contents of the test-tube were then homogenized manually for $1 \mathrm{~min}$, centrifuged ( $4000 \mathrm{rev} . / \mathrm{min}, 10 \mathrm{~min}$ ), and the supernatant liquid was separated. The induced tissue damage was biochemically characterized by measuring the activity of the tissue enzyme LDH at $412 \mathrm{~nm}$ (Spectronic 1001; Milton Roy, Hasselroth, Germany) using a substrate of pyruvic acid and NADH. The results were normalized for the tissue dry weight (A. Rubinstein, A. Kakunda and R. Kohen, unpublished results). The second biochemical variable that was quantitatively detected was the intracellular mucosal $\mathrm{K}^{+}$level. A $1 \mathrm{ml}$ sample from the homogenized tissue was acidified with $250 \mu 19 \mathrm{M}-\mathrm{HCl}$, mixed in a vortex mixer and diluted to $3 \mathrm{ml}$ with double-distilled water. The $\mathrm{K}^{+}$content was monitored by atomic absorption (Perkin Elmer) as described elsewhere (Korbashi et al. 1986).

Each experiment was repeated at least four times, and the reported results are the means and standard deviations of the replicates.

\section{Statistical analysis}

A Kruskal-Wallis test was performed to check whether the various groups of rats were from different populations. A difference was considered to be statistically significant when $P<0.05$. When the difference between the groups was validated, a Mann-Whitney U test was used to analyse the significance of the differences between the obtained data $(P<0.05)$.

\section{RESULTS}

Our experimental protocol postulated that exposure of the rat jejunal mucosa to continuous efflux of $\mathrm{ROO}^{\circ}, \mathrm{OH}^{*}$ and superoxide radicals ruptures the cells' membrane integrity, thus causing leakage of endocellular components. Continuous efflux of radicals 

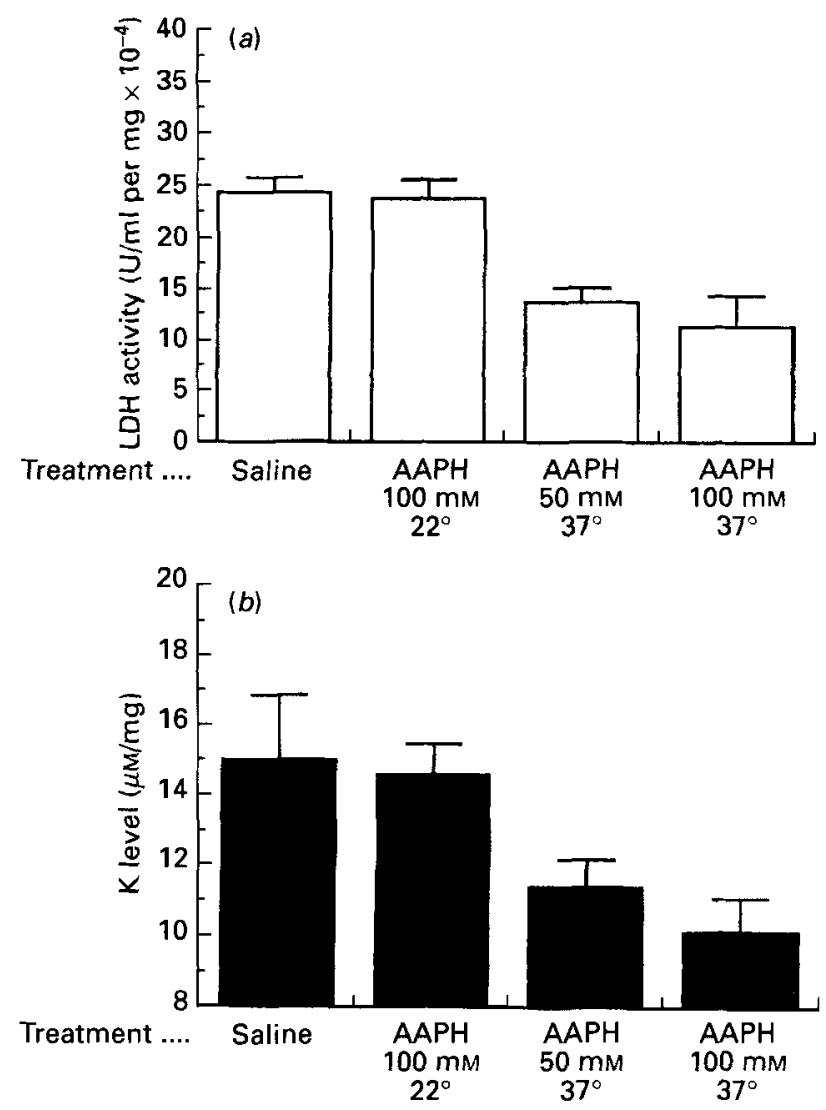

Fig. 1. The damage induced to the jejunal mucosa by peroxyl radicals as indicated by: $(a)$ the reduction in enterocyte lactate dehydrogenase (EC I.1.1.27; LDH) activity of rat jejunum perfused with 25,50 and $100 \mathrm{~mm}$ of peroxyl radical inducer 2,2'azobis(2-amidinopropane dihydrochloride) (AAPH) at $37^{\circ}$, and with $100 \mathrm{mM}-$ AAPH at $22^{\circ} ;(b)$ the reduction in cellular $\mathrm{K}^{+}$levels of rat jejunum perfused with the same concentrations of AAPH at $37^{\circ}$, and with $100 \mathrm{~mm}-\mathrm{AAPH}$ at $22^{\circ}$. The perfusion rate was $1 \mathrm{ml} / \mathrm{min}$ for $60 \mathrm{~min}$. For details of procedures, see pp. 791-792.

was achieved by using the closed-loop perfusion technique. The damage was determined quantitatively by monitoring the remaining activity of the enterocyte enzyme LDH and the cellular levels of $\mathrm{K}^{+}$. Validation of the method was achieved by demonstrating that the damage induced by the AAPH is concentration dependent; this is shown in Fig. $1(a)$. Concentrations of 50 and 100 mM-AAPH resulted in lower LDH activities; 14.07 (SD 1.1) and $11.3(\mathrm{sD} 2.7) \mathrm{U} / \mathrm{ml}$ per $\mathrm{mg} \times 10^{-4}$ for 50 and $100 \mathrm{~mm}$-AAPH respectively, compared with 24.2 (SD 1.5) $\mathrm{U} / \mathrm{ml}$ per $\mathrm{mg} \times 10^{-4}$ for the saline control. Since LDH is located inside the enterocytes it can be deduced that the decrease in its activity is a result of a damaged cell membrane through which the LDH leaked during the course of the perfusion. Fig. 1 $(b)$ shows a similar reduction in the cellular $\mathrm{K}^{+}$. Perfusion of 50 and $100 \mathrm{mM}-\mathrm{AAPH}$ resulted in lower $\mathrm{K}$ levels: 11.5 (SD 0.89) and 10.12 (SD 1.15) $\mu \mathrm{M}$ for 50 and $100 \mathrm{mM}$-AAPH respectively, compared with levels of 15.0 (SD 2) $\mu \mathrm{M}-\mathrm{K}$ in the control experiments (perfusion with saline).

The non-oxidative stress toxicity of the AAPH, as a possible cause of the reduction in the LDH activity, was studied separately, where the temperature of the perfused solution was lowered to $22^{\circ}$. This led to a decrease in the ROO' induction (Yamamoto et al. 1985). No 


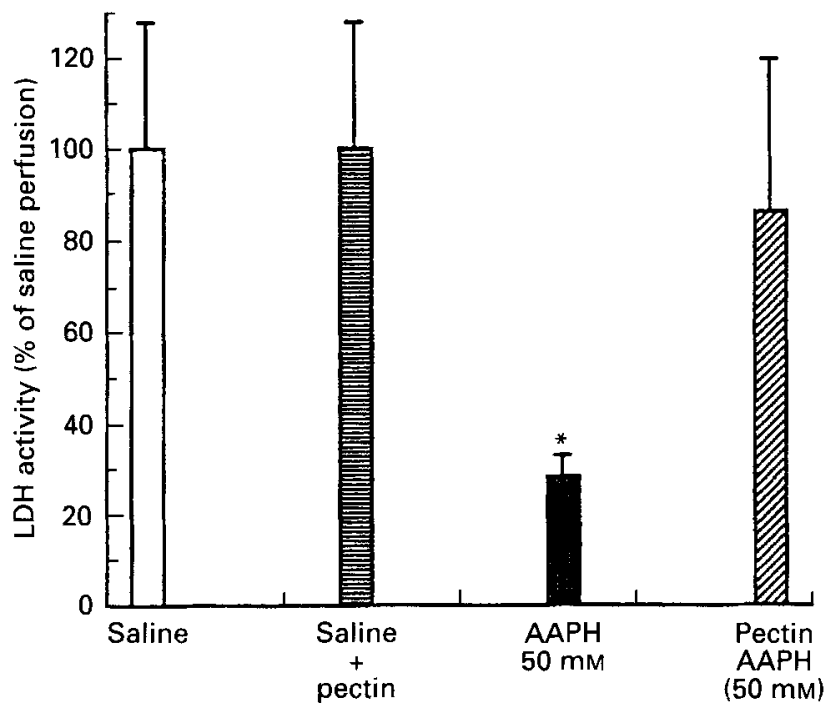

Fig. 2. The effect of pectin on the damage induced to the rat jejunal mucosa by peroxyl radicals based on the remaining relative activity of lactate dehydrogenase $(E C 1.1 .1 .27 ; \mathrm{LDH})$. The peroxyl radicals were induced by perfusion of 2,2'-azobis(2-amidinopropane dihydrochloride) (AAPH; $50 \mathrm{~mm}$ ). The perfusion rate was $1 \mathrm{ml} / \mathrm{min}$ and the perfusion period was $60 \mathrm{~min}$. Pectin $(20 \mathrm{~g} / \mathrm{l})$ in saline was perfused for $30 \mathrm{~min}$ before the perfusion with AAPH. Values were normalized to tissue dry weight. Values are means and standard deviations represented by vertical bars for four determinations. Mean value was significantly different from those for saline + pectin and pectin then AAPH treatment groups; ${ }^{*} P<0.05$. For details of procedures, see pp. 791-792.

\section{Table 1. Mucosal potassium in the perfused rat intestine}

(The rat jejunum was perfused for $60 \mathrm{~min}$ at a rate of $1 \mathrm{ml} / \mathrm{min}$, after which time the mucosal tissue was removed and analysed for $\mathrm{K}^{+}$(see p. 792 ). Pectin $(20 \mathrm{~g} / \mathrm{l})$ in saline was perfused for 15 min before the perfusion with $50 \mathrm{~mm}-2,2^{\prime}$-azobis(2-amidinopropane dihydrochloride) (AAPH))

\begin{tabular}{lcc}
\hline Treatment & $\mathrm{K}^{+}(\%)^{*}$ & Protection $(\%) \dagger$ \\
\hline Saline $(9 \mathrm{~g} \mathrm{NaCl} / \mathrm{l})$ & 100 & \\
Pectin-saline & 96 & \\
AAPH & 77 & 24.6 \\
Pectin-AAPH & 96 & 26 \\
\hline
\end{tabular}

* The measured $\mathrm{K}^{+}$levels (normalized to tissue dry weight) are expressed as a percentage of the levels found in the control saline perfusion experiment.

$\dagger$ The percentage protection was calculated according to the following equation:

$$
P=\left(\frac{\mathrm{K}_{\mathrm{P}+\mathrm{A}}^{+}}{\mathrm{K}_{\mathrm{A}}^{+}}-1\right) \times 100,
$$

where $P$ is the percentage protection, $\mathrm{K}_{\mathrm{P}+\mathrm{A}}^{+}$is the relative amount of mucosal $\mathrm{K}^{+}$after pectin perfusion followed by AAPH perfusion, $\mathrm{K}_{\mathrm{A}}^{+}$is the relative level of mucosal $\mathrm{K}^{+}$after AAPH perfusion.

epithelial damage was detected in these experiments (Fig. 1). To avoid LDH inactivation after mucosal scraping the various samples taken for analysis of $\mathrm{LDH}$ activity were immediately washed with saline and kept in an ice bath. As shown in Fig. 1, no LDH inactivation was detected at low temperature.

We monitored the intracellular LDH activity and $\mathrm{K}^{+}$levels in the mucosa, and not in the perfusate, to avoid artifacts resulting from the presence of these two markers in the luminal 

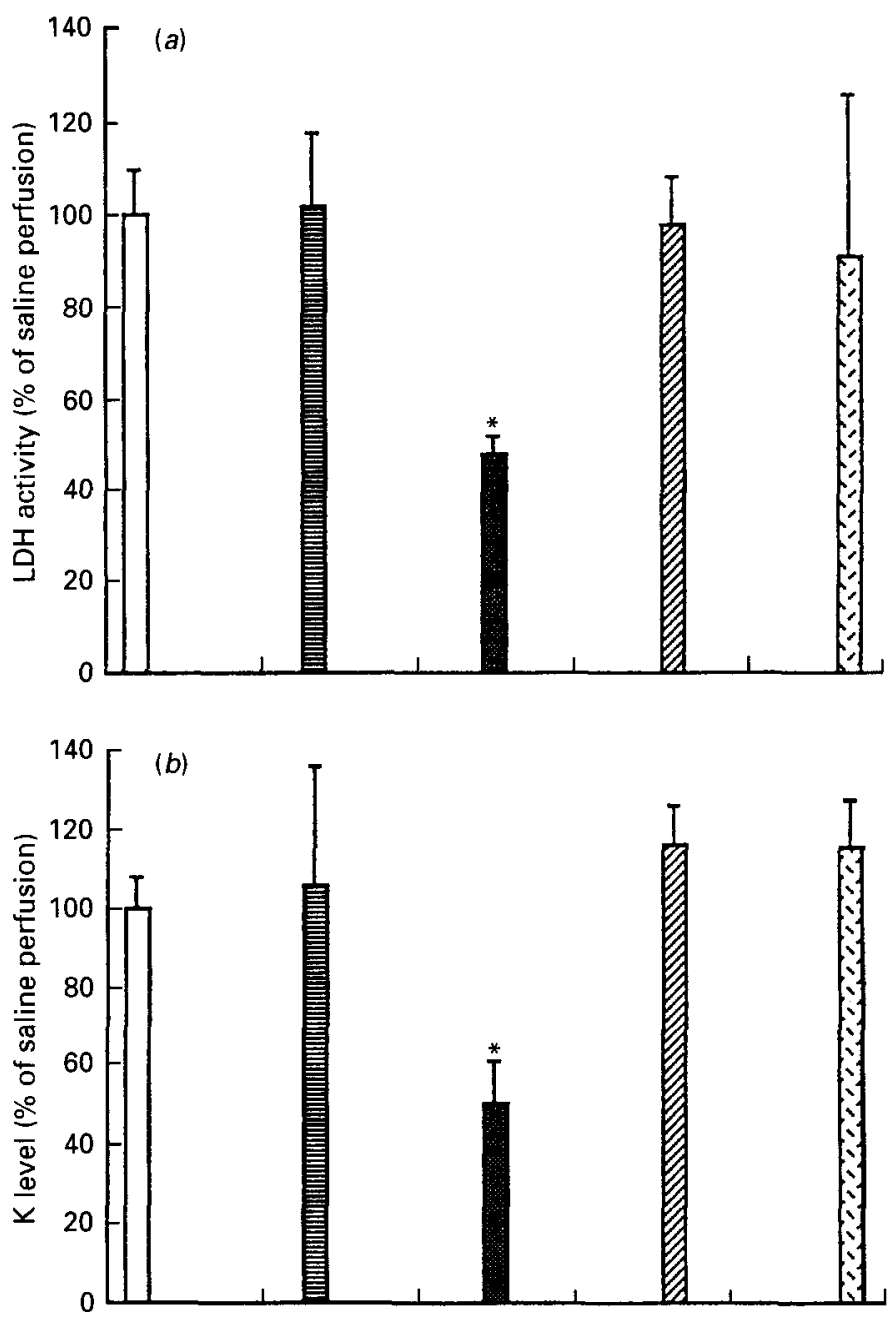

Fig. 3. The effect of pectin on the damage induced to rat jejunal mucosa by hydroxyl radicals based on (a) the relative activity of the enzyme lactate dehydrogenase $(E C 1.1 .1 .27 ; \mathrm{LDH})$ and $(b)$ cellular $\mathrm{K}^{+}$levels. The hydroxyl radicals were induced by the addition of $\mathrm{FeSO}_{4}(10 \mathrm{~mm})$ complexed with EDTA $(1 \mathrm{~mm})$ to a reaction mixture containing xanthine $(6 \mathrm{mM} ; \mathrm{X})$ and xanthine oxidase $(E C 1.1 .3 .22 ; 3 \mathrm{U} ; \mathrm{XO})$. This mixture was perfused for $30 \mathrm{~min}$. When pectin $(20 \mathrm{~g} / \mathrm{l})$ was present, it was perfused for $30 \mathrm{~min}$ before the perfusion of the hydroxyl radical-inducing medium. Values were normalized to tissue dry weight. Values are means and standard deviations represented by vertical bars for four determinations using infusions of saline ( $\square$ ), $\mathrm{X}-\mathrm{XO}\left(\right.$ 員), $\mathrm{X}-\mathrm{XO}-\mathrm{FeSO}_{4}($ 圆), $\mathrm{FeSO}_{4}(\bigotimes)$, or $\mathrm{X}-\mathrm{XO}-\mathrm{FeSO}_{4}$ and pectin (四). Mean value was significantly different from those for $\mathrm{X} / \mathrm{XO}$ and $\mathrm{Fe}^{2+}-$ EDTA treatment groups; $* P<0 \cdot 05$. For details of procedures, see pp. 791-792.

compartment of the mucosa (for instance, as a result of bacterial presence). In addition, experiments in our laboratory revealed that LDH can be inactivated easily when reacted directly with $\mathrm{O}$ reactive species ( $\mathrm{R}$. Kohen and $\mathrm{D}$. Gilhar, unpublished results). Higher concentrations of AAPH $(50 \mathrm{~mm})$ caused immediate inactivation of $\mathrm{LDH}$ compared with $10 \mathrm{mM}$, which inactivated $90 \%$ of the $\mathrm{LDH}$ within $20 \mathrm{~min}$. To exclude the possibility that the AAPH diffuses into the enterocytes and interacts with LDH without harming the cell membrane, we compared the rate of its uptake with the rate of $\mathrm{LDH}$ inactivation. Rat 


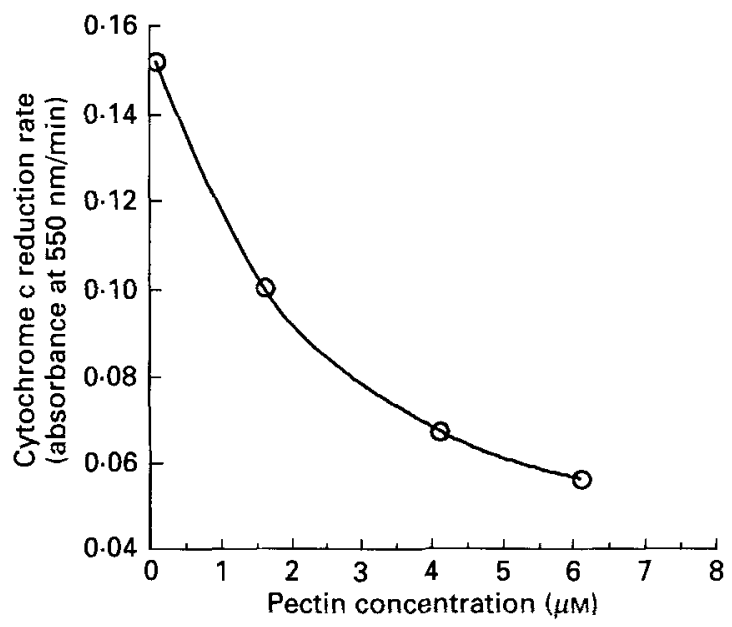

Fig. 4. The effect of pectin on the reduction of cytochrome $\mathrm{c}$ by superoxide radicals. The reaction mixture contained xanthine $(1.2 \mathrm{mM})$, xanthine oxidase $(E C 1.1 .3 .22 ; 0 \cdot 01 \mathrm{U})$ and cytochrome $\mathrm{c}(50 \mu \mathrm{M})$. Various levels of pectin were added at the beginning of the reaction and the reduction of the cytochrome $c$ was determined spectrophotometrically at $550 \mathrm{~nm}$. For details of procedures, see pp. 791-792.

mucosa was mounted in a modified Ussing chamber (Grass \& Sweetana, 1988), AAPH (50 mM) in saline was placed in the donor side, and its appearance kinetics were monitored spectrophotometrically over a period of $60 \mathrm{~min}$ in the acceptor side. The results indicated that the rate of AAPH transport across the mounted epithelium was much slower than the $\mathrm{LDH}$ inactivation (almost no transport during $60 \mathrm{~min}$; values not shown).

Fig. 2 demonstrates the mucosal LDH levels at the end of the various treatments. The activity after saline perfusion was referred to as $100 \%$. No significant difference in the LDH activity was observed following perfusion with saline compared with untreated rats. Under the same conditions, when aqueous pectin solution $(20 \mathrm{~g} / 1)$ was perfused as a control in the rat jejunum, the enzyme activity was comparable with that obtained following perfusion with saline (100 (sD 28) \% of the saline control). Perfusion of $50 \mathrm{~mm}$ solution of AAPH at $37^{\circ}$ caused a mean reduction of 72 (SD 5) \% in the enzyme activity. However, when pectin solution $(20 \mathrm{~g} / 1)$ was perfused before the perfusion of the AAPH (50 mM), no significant reduction in the $\mathrm{LDH}$ activity was observed compared with the control (saline) experiments (86 (SD 33) \% of the activity when saline was perfused). Because of viscosity limitation, higher concentrations of pectin solutions could not be perfused, and assessment of the ability of larger amounts of pectin to protect the jejunal mucosa against oxidative stress damage could not be performed.

The protection characteristics of pectin, as reflected by $\mathrm{K}^{+}$levels in the epithelial mucosa of the perfused jejunum, are shown in Table 1. While perfusion of AAPH resulted in a $23 \%$ decrease in $\mathrm{K}^{+}$levels compared with those for saline treatment, no damage was observed when pectin was introduced to the system before AAPH treatment; a finding which supports the results obtained by monitoring the activity of LDH in the various experiments.

Fig. 3 shows that when the rat jejunum was exposed to the mixture of xanthine $(6 \mathrm{~mm})$ and xanthine oxidase $(3 \mathrm{U})$, which induced the superoxide radicals, neither reduction in $\mathrm{LDH}$ activity nor in the $\mathrm{K}^{+}$levels were recorded. The values for the $\mathrm{LDH}$ activity were 102 (SD 16) \% of the saline control (Fig. 3(a)), and for K levels 106 (SD 30) \% of the saline control (Fig. 3(b)). However, introduction of chelated Fe ${ }^{2+}(10 \mathrm{~mm}$-EDTA-1 mM-ferrous sulphate) to the reaction mixture containing xanthine $(6 \mathrm{mM})$ and xanthine oxidase $(3 \mathrm{U})$ 
resulted in a significant reduction in cellular LDH activity of the enterocytes (48 (SD 4) \% of the saline control (Fig. 3(a)). A similar reduction in $\mathrm{K}^{+}$levels was also observed $(50$ (SD 11) $\%$ of the saline control; Fig. 3(b)). These results indicate that the induced $\mathrm{OH}^{*}$ caused mucosal damage, reflected by leakage of $\mathrm{K}^{+}$and of the enzyme LDH from the epithelium mucosal cells. When pectin solution was perfused before the reaction mixture containing the same amounts of xanthine, xanthine oxidase and $\mathrm{Fe}^{2+}$ EDTA, no significant damage was recorded as reflected by the LDH activity $(91$ (SD 35) \% of the saline control (Fig. 3(a)) and $\mathrm{K}^{+}$levels (115 (SD 12) \% of the saline control (Fig. 3(b)). No reduction in $\mathrm{LDH}$ activity and in $\mathrm{K}^{+}$levels was recorded following perfusion of $\mathrm{Fe}^{2+}$-EDTA (10 mM: $1 \mathrm{~mm}$ ) alone or EDTA ( $1 \mathrm{~mm}$ ) alone. These control experiments were carried out to exclude the possibility of membrane damage by chelation of ions by EDTA (not shown).

The ability of the pectin to react with the superoxide radicals as measured by the kinetics of the reduction reaction of cytochrome $\mathrm{c}$ is shown in Fig. 4. Pectin was shown to be an efficient scavenger of superoxide radicals. Pectin in saline $(1 \cdot 5,4$ and $6 \mu \mathrm{M})$ resulted in an increase in the scavenging capacity by 35,56 and $61 \%$ respectively.

\section{DISCUSSION}

The intestinal epithelium is a major target for the deleterious action of $\mathrm{O}$ reactive species when induced in the intestinal lumen. The oxidative damage in the gastrointestinal mucosa is mainly characterized by the lipid peroxidation process (Granger et al. 1986; Grisham et al. 1987). During this process a variety of O species, such as ROO', lipid hydroperoxide and alkoxy radicals are formed. ROO', for example, can inactivate proteins, damage biological membranes and impair DNA, thus causing the initiation of deleterious processes (Ames, 1983; Esterbauer et al. 1988; Halliwell, 1989). These processes may be initiated by oxidizing agents present in the diet, or as a consequence of pathological situations such as inflammatory diseases. Lipid peroxidation can also occur in food products before their ingestion into the human body. In the latter case lipid peroxidation products (aldehydes and ketones) may cause biological damage at a later stage. The high consumption of fat, as well as the increased consumption of fried food and fatty acid, in our diet may, therefore, result in pathological disturbance to the gastrointestinal tract, where the oxidized fat is digested and absorbed (Ames, 1983; Ames \& Saul, 1985).

In the present study we used several $O$ radical sources. The azo compound AAPH was used to induce ROO' in the perfused rat jejunum. ROO', in turn, can cause direct or indirect damage to the jejunal mucosa. We introduced the AAPH to the rat intestinal epithelium by using the closed-loop recirculating perfusion technique. In this system the jejunal epithelium is exposed to the radical initiator in close and continuous contact. The results obtained indicate that $\mathrm{ROO}^{\circ}$ can cause severe damage to the mucosal cells, which is reflected in a decrease in the activity of the cellular enzyme LDH and in the cellular level of $\mathrm{K}^{+}$(Figs. 1 and 2 and Table 1). As described previously, in order to avoid possible interference of traces of $\mathrm{LDH}$ of luminal origin we chose to conduct our measurements in the cellular compartment rather than in the perfusate. The induced ROO' can interact directly with the LDH to inactivate it. However, the inactivation occurs very rapidly, much more rapidly than diffusion of AAPH into the enterocytes; therefore, measurement of the residual $\mathrm{LDH}$ activity in the tissue itself is appropriate. The enterocyte K-levels after AAPH perfusion support the findings obtained with LDH activity (Table 1, Fig. 1(b)). It was found that residual LDH activity in the tissue is proportional to the concentration of the perfused AAPH, as demonstrated in Fig. $1(a$ and $b)$.

The influence of superoxide and $\mathrm{OH}^{*}$ on the rat jejunal mucosa is summarized in Fig. 3. 
While superoxide radicals did not cause any damage, $\mathrm{OH}^{\bullet}$ were induced by the addition of chelated $\mathrm{Fe}^{2+}$ to the xanthine-xanthine oxidase system and caused severe damage as indicated by cellular LDH activity and $\mathrm{K}$ levels. This observation is important since the intestinal epithelium is routinely exposed to $\mathrm{Fe}^{2+}, \mathrm{H}_{2} \mathrm{O}_{2}$ and reducing agents such as ascorbic acid, originating from dietary sources; therefore, induced $\mathrm{OH}^{*}$ may cause oxidative stress damage to the intestinal mucosa as indicated in our study.

In the second part of the present study the ability of pectin to prevent induced oxidative stress damage was studied. The role of pectin in intestinal pathogenesis, e.g. colon carcinogenesis, is controversial. Watanabe et al. (1979) found a protective effect when $150 \mathrm{~g}$ pectin $/ \mathrm{kg}$ was used in azoxymethane-induced rats, while Bauer et al. (1981) claimed that $50 \mathrm{~g}$ slightly and highly methoxylated pectin increased the multiplicity of colon tumours in rats treated with methylnitrosourea. The pectin is also known to bind $\mathrm{Ca}^{2+}$ in the gut (Cummings et al. 1979) although it does not affect the total body Ca balance, probably because of pectin digestion in the colon. When the influence of pectin on small intestine mucosal mass, morphology and cytokinetics was studied in the rat it was found that modulation of small intestine mucosal structure and growth appears to be mediated through changes in cell proliferation directed by the amount of pectin presented in the diet (Jacobs, 1983). Brown et al. (1979) suggested that pectin may increase the epithelial cell turnover in the intestine. Flourie et al. (1984) have claimed that pectin increases the thickness of the unstirred water layer, leading to a decrease in absorption of nutrients such as glucose.

Our findings reveal that pectin can prevent the damage induced by oxidative stress (Figs. 2 and 3 and Table 1) by a mechanism which is not yet clear. Pectin may act as an antioxidant in several ways. It may directly scavenge ROO', thus avoiding intestinal mucosal contact with this noxious substance. It has been demonstrated already that natural mucopolysaccharides such as gastric mucin can scavenge $\mathrm{OH}^{\cdot}$ (Grisham et al. 1987). If scavenging is the mechanism by which pectin protects the epithelial mucosa, a synergistic effect may be achieved. Pectin may also act as a chelating agent of loosely bound transition metals in the lumen. By doing so it can prevent them from participating in the metalmediated reaction which might catalyse the transformation of $\mathrm{ROO}^{-}$to more potent radicals (e.g. alkoxy radicals, $\mathrm{OH}^{*}$; Ames \& Saul, 1985). We demonstrated that the damage induced to the rat jejunal mucosa by induced $\mathrm{OH}^{-}$in the lumen is also reduced by pectin (Fig. 3( $a$ and $b)$ ). $\mathrm{OH}^{-}$is an extremely active $\mathrm{O}$ species and may interact with almost everything in its surroundings. The source for the highly reactive $\mathrm{OH}^{\cdot}$ may be the metalmediated Haber-Weiss reaction in which $\mathrm{H}_{2} \mathrm{O}_{2}$ reacts with reduced metal ions to give the reactive species. $\mathrm{H}_{2} \mathrm{O}_{2}$ is formed by the spontaneous dismutation of superoxide radicals. Fig. 4 shows that pectin reacts with the superoxide radical itself, and by doing so, prevents its dismutation to $\mathrm{H}_{2} \mathrm{O}_{2}$.

Another possible explanation for the observed protection is the increase in the thickness, or viscosity, of the unstirred water layer adjacent to epithelial wall (Blackburn \& Johnson, 1983; Flourie et al. 1984). This may result in a decrease in the diffusion of ROO' towards the mucosal tissue, leading to a reduction in induced damage. It is worth noting that in previous publications it was reported that chronic consumption of pectin by rats (through diet) caused crypt hyperplasia associated with both reduction in brush-border enzyme content and activity (Brown et al. 1979; Jacobs, 1983). However, elucidation of the exact mechanism of pectin needs further experiments and discussion. Our findings, which were observed during acute administration of pectin, call for further studies in order to clarify the exact mechanisms of pectin protection and to investigate whether these results can be repeated when chronic intake of pectin is used. 
This work was supported by a research grant from the Israel Cancer Association (38/90), PO Box 20018, Tel Aviv, Israel. It is included in the dissertation project of V.S. as partial fulfilment of the MSc degree requirements of the Hebrew University of Jerusalem.

\section{REFERENCES}

Ames, B. N. (1983). Dietary carcinogens and anticarcinogens. Science 221, 1256-1263.

Ames, B. N., Cathcart, R., Schwiers, E. \& Hochstein, P. (1981). Uric acid provides an antioxidant defense in humans against oxidant- and radical-caused aging and cancer: A hypothesis. Proceedings of the National Academy of Sciences, USA 78, 6858-6862.

Ames, B. N. \& Saul, R. L. (1985), Oxidative DNA damage, aging and cancer. In Diet and Human Carcinogenesis, pp. 25-34 [J. V. Joossens, M. J. Hill \& J. Geboers, editors]. Amsterdam: Elsevier.

Anderson, J. W. (1985). Physiological and metabolic effects of dietary fiber. Federation Proceedings 44, $2902-2906$.

Bauer, H. G., Asp, N.-G., Dahlqvist, A., Fredlund, P. E., Nyman, M. \& Oste, R. (1981). Effects of two kinds of pectins and guar gum on 1,2-dimethylhydrazine initiation of colon tumors and on fecal $\beta$-glucuronidase activity in the rat. Cancer Research 41, 2518-2523.

Bijlani, R. L. (1985). Dietary fibre: consensus and controversy. Progress in Food and Nutrition Science 9, 343-393.

Blackburn, N. A.\& Johnson, I. T. (1983). The influence of guar gum on the movements of inulin, glucose and fluid in rat intestine during perfusion in vivo. Pfügers Archiv 397, 144-148.

Brown, R. C., Kelleher, J. \& Losowsky, M. S. (1979). The effect of pectin on the structure and function of the rat small intestine. British Journal of Nutrition 42, 357-365.

Burkitt, D. P. (1971). Epidemiology of cancer of the colon and rectum. Cancer 28, 3-13.

Chance, B., Sies, H. \& Boveris, A. (1979). Hydroperoxide metabolism in mammalian organs. Physiological Reviews 59, 527-605.

Cross, C. E., Halliwell, B. \& Allen, A. (1984). Antioxidant protection: a function of tracheobronchial and gastrointestinal mucus. Lancet i, 1328-1330.

Cummings, J. H., Southgate, D. A. T., Branch, W. J. \& Wiggins, H. S. (1979). The digestion of pectin in human gut and its effect on calcium absorption and large bowel function. British Journal of Nutrition 41, 477-485.

Esterbauer, H., Zollner, H. \& Schaur, R. J. (1988). Hydroxyalkenals: cytotoxic products of lipid peroxidation. ISI Atlas of Scientific Biochemistry 1, 311-315.

Flourie, B., Vidon, N., Florent, C. \& Bernier, J. J. (1984). Effect of pectin on jejunal glucose absorption and unstirred layer thickness in normal man. Gut 25, 936-941.

Granger, D. N., Hernandez, L. A. \& Grisham, M. B. (1986). Reactive oxygen metabolites: mediators of cell injury in the digestive system. Viewpoints of Digestive Diseases 18,13-16.

Grass, G. M. \& Sweetana, S. A. (1988). In vitro measurement of gastrointestinal tissue permeability using a new diffusion cell. Pharmaceutical Research 5, 372-376.

Grisham, M. B., Riter, C., Smith, B. F., Lamont, J. T. \& Granger, D. N. (1987). Interaction between oxygen radicals and gastric mucine. American Journal of Physiology 253, G93-G96.

Halliwell, B. (1989). Free radicals, reactive oxygen species and human disease: a critical evaluation with special reference to atherosclerosis. British Joumal of Experimental Pathology 70, 737-757.

Halliwell, B. (1990). How to characterize a biological antioxidant. Free Radicals Research Communications 9 , $1-32$.

Halliwell, B. \& Gutteridge, J. M. C. (editors) (1985). Free Radicals in Biology and Medicine. Oxford, Clarendon Press.

Jacobs, L. R. (1983). Effect of dietary fiber on mucosal growth and cell proliferation in the small intestine of the rat: a comparison of oat bran, pectin and guar with total fiber deprivation. American Journal of Clinical Nutrition 37, 954-960.

Kinlen, L. J. (1983). Fat and cancer. British Medical Journal 286, 1081-1082.

Korbashi, P., Kohen, R., Katzhendler, J. \& Chevion, M. (1986). Iron mediates paraquat toxicity in Escherichia coli. Journal of Biological Chemistry 261, 12472-12476.

Lewis, L. D. \& Fordtran, J. S. (1975). Effect of perfusion rate on absorption, surface area, unstirred water layer thickness, permeability, and intraluminal pressure in the rat ileum in vivo. Gastroenterology 68, 1509-1516.

Lutsky, I., Aizer, F. \& Mor, N. (1984). The Sabra rat: Definition of a laboratory animal. Israel Journal of Medical Sciences 20, 603-612.

Navok, T. \& Chevion, M. (1984). Transition metals mediate enzymatic inactivation caused by favism-inducing agents. Biochemistry and Biophysics Research Communications 122, 297-301.

Oliver, C. N., Ahn, B., Moermant, E. J., Goldstein, S. \& Stadtman, E. R. (1987). Age-related changes in oxidized proteins. Journal of Biological Chemistry 262, 5488-5491.

Pryor, W. A. (ed.) (1976). Free Radicals in Biology. New York: Academic Press.

Samuni, A., Winkelsberg, D., Pinson, A., Hahn, S. M., Mitchel, J. B. \& Russo, A. (1991). Nitroxide stable radicals protect beating cardiomyocytes against oxidative damage. Journal of Clinical Investigation 87 , $1526-1530$. 
Szabo, S. \& Pfiffer, C. J. (1989). Ulcer Disease: New Aspects of Pathogenesis and Pharmacology. Boca Raton: CRC.

Towle, G. A. \& Christensen, O. (1973). Pectin. In Industrial Gums, Polysaccharides and their Derivatives, pp. $429-461$ [R. L. Whistler and J. N. BeMiller, editors]. New York: Academic Press.

Trowell, H. \& Burkitt, D. P. (1985). Dietary Fiber, Fiber-Depleted Foods and Disease [K. Heaton, editor]. New York: Academic Press.

Watanabe, K., Reddy, B. S., Weisburger, J. H. \& Kritchevsky, D. (1979). Effect of alfalfa, pectin, and wheat bran on azoxymethane-methylnitrosourea-induced colon carcinogenesis in F344 rats. Journal of National Cancer Institute 63, 141-145.

Wolfgang, G. H., Holly, R. A., Donarski, W. J. \& Petry, T. W. (1991). Inhibition of diquat-induced lipid peroxidation and toxicity in precision-cut rat liver slices by novel antioxidants. Toxicology and Applied Pharmacology 108, 321--329.

Yamamoto, Y., Niki, E., Eguchi, J., Kamiya, Y.\& Shamasaki, H. (1985). Oxidation of biological membranes and its inhibition. Free radical chain oxidation of erythrocyte ghost membrane by oxygen. Biochimica et Biophysica Acta 819, 29-36. 